\title{
Epidemiology of Eosinophilic Esophagitis
}

\author{
Petr Hruz \\ Department of Gastroenterology, University Hospital Basel, Basel, Switzerland
}

\author{
Key Words \\ Eosinophilic esophagitis · Incidence · Prevalence · \\ Epidemiology
}

\begin{abstract}
Eosinophilic esophagitis (EoE) is an allergy-associated disease defined clinically by esophagus-related symptoms in combination with a dense esophageal eosinophilia, both of which are unresponsive to prolonged acid suppression with proton pump inhibitors. Over the last two decades EoE has increasingly been recognized in various geographical areas (mostly industrialized countries) with high socioeconomic development. The prevalence rate is increasing and reaches up to 50 patients per 100,000 inhabitants in some indicator regions. Whether this increased prevalence is due to a real increase in incidence, a result of increased awareness by health care providers or because of the nonfatal nature of EoE adding more and more cases to the patient pool is still a matter of controversy. Several studies have consistently demonstrated a male predominance in EoE, with a male-tofemale risk ratio of $3: 1$. The average age at diagnosis ranges between 30 and 50 years and suggests that EoE is a disease of the middle-aged man. It can affect patients of every race, but the disease is more common among Caucasians. In both children and adults, EoE has been clearly associated with allergies to food and aeroallergens, and most EoE patients present with a personal allergic background (e.g. asthma, rhinoconjunctivitis or oral allergy syndrome). In conclusion, knowledge of epidemiologic parameters of EoE is crucial for
\end{abstract}

identifying risk factors as well as pathogenic mechanisms, planning preventive measures and determining optimal treatment strategies.

(c) 2014 S. Karger AG, Base

\section{Eosinophilic Esophagitis: A New Esophageal Disease with Increasing Incidence and Prevalence}

Epidemiology (Greek terms, 'epi' = among; 'demos' = people and 'logos' = study) characterizes factors affecting the health and the illness of a population. It serves as the foundation of any intervention made in public health as well as in clinical practice, and relies on a number of scientific disciplines such as medicine, biology, geography and social science. The clinical and socioeconomic relevance of any disease is determined by the knowledge of its epidemiologic parameters. In particular, it is the incidence and prevalence among a certain population. This knowledge is crucial for identifying risk factors as well as understanding pathogenetic mechanisms, planning preventive measures and optimizing treatment strategies.

Eosinophilic esophagitis (EoE) is a relatively new immune-mediated inflammatory disorder of the esophagus $[1,2]$. It is clinicopathologically characterized by esophageal symptoms in combination with dense esophageal eosinophilia [3]. Several epidemiological reports have recently suggested that EoE is being diagnosed with a dramatically increasing frequency over the last years in westernized/industrialized countries. So far, the vast ma-

\section{KARGER}

E-Mail karger@karger.com

www.karger.com/ddi
(C) 2014 S. Karger AG, Basel

0257-2753/14/0322-0040\$39.50/0
Petr Hruz, MD, PhD

Petersgraben 4

$\mathrm{CH}-4031$ Basel (Switzerland)

E-Mail petr.hruz@usb.ch 
jority of studies addressing epidemiological questions in EoE rely on retrospective analysis of pathology reports with reexaminations of biopsy specimens or on analysis of endoscopy reports. In recent years, however, more and more population-based epidemiologic information from geographically confined regions with longitudinal analysis is being provided from which more substantive epidemiologic statements can be made.

\section{Prevalence of Esophageal Eosinophilia}

Eosinophils are found in concentrations of up to 350 cells $/ \mathrm{mm}^{3}$ in the peripheral blood of healthy individuals and are present in the mucosa of all areas of the digestive tract, except the esophagus $[4,5]$. The presence of eosinophils in the esophagus is therefore commonly associated with disease. Of note, esophageal eosinophilia is not exclusively limited to EoE. Eosinophilic infiltration of the esophagus has been reported in patients with gastroesophageal reflux disease, Barrett's esophagus and rare conditions such as drug-induced esophagitis, infectious and parasitic infection, vasculitis, Crohn's disease, and eosinophilic gastroenteritis affecting the esophagus. Esophageal eosinophilia therefore requires a process of differential diagnosis and cannot, a priori, be equated with EoE $[4,6]$.

A retrospective analysis and histologic reevaluation of pediatric esophageal biopsy specimens with reflux esophagitis obtained between 1982 and 1999 revealed a substantial number of patients who had $>15$ eosinophils/ high-power field (HPF). This implicated that esophageal eosinophilia may have been an underrecognized finding already in the late 1980s and 1990s [7]. In a prospective cross-sectional population-based study of the adult Swedish population (mean age: 54 years, $49 \%$ men), the prevalence of esophageal eosinophils in the general population was determined by taking biopsies of the distal part of esophagus [5]. Eosinophilic infiltration of the esophageal epithelium was arbitrarily classified as 'low grade' when 1-4 eosinophils/HPF were found, 'possible EoE' with 5-14, 'probable EoE' with 15-20 and 'definite EoE' with $\geq 20$. The prevalence of any eosinophil infiltration in the most distal parts of the esophagus was $4.8 \%$ in the general population, predominantly among men (63\%), with $54 \%$ of these subjects reporting reflux symptoms. Therefore, the presence of esophageal eosinophils may be more common in the general population than expected. In only 4 subjects $(0.4 \%$ of the general population) were $\geq 20$ eosinophils/HPF found, and 3 of them reported trouble- some reflux symptoms without any endoscopic characteristics of erosive esophagitis. Only 1 subject with 'definite EoE' presented with asthma and dysphagia, which suggests this patient was suffering from clinicopathologically defined EoE. 'Probable EoE' was present in 7 and 'possible EoE' in 25 subjects. On evaluation of two biopsy sites (taken at $2 \mathrm{~cm}$ above and at the Z-line), the presence of eosinophils was positively associated with erosive esophagitis, hiatus hernia, narrowing of the esophageal lumen and esophageal ulcer, thereby suggesting that the presence of esophageal eosinophils, especially in the distal esophageal portions, may be a manifestation of reflux disease. Conversely, patients with $<15$ eosinophils/HPF on histological evaluation may present with similar endoscopic findings and clinical symptoms as patients meeting the consensus definition of EoE. This raises an important question about the histological cutoff value of eosinophils/HPF for the diagnosis of EoE and, as a result, the pathophysiological contribution of esophageal eosinophilia to the development of EoE [8].

\section{Incidence and Prevalence of EoE Based on Endoscopy and Histopathology Reports}

Increasing prevalence of EoE has mostly been described by studies based on retrospective evaluation of pathological or endoscopic databases. Substantially increasing incidence rates in both pediatric and adult patients have been shown in a Dutch cross-sectional study using the nationwide network and registry of histopathology reports describing esophageal eosinophilia from 1996 through 2010 [9]. By the end of 2003, a prevalence rate of 43 per 100,000 children was reached in the pediatric population of Hamilton County, with a substantial increase in the years 2000-2003 [10]. Other studies on retrospective review of upper endoscopy procedure or histopathology reports of children also describe increasing prevalence rates during the last years [11-14]. In a prospective evaluation of children and infants in Southern Denmark (pediatric population of 256,164; age: 0-16 years) with symptoms of gastroesophageal reflux disease during an 18 -month period, 6 patients were diagnosed with EoE, corresponding to an annual incidence rate of 1.6 per 100,000 children [15]. A recent review summarizing 25 epidemiological studies concerning incidence and prevalence of EoE in children showed that the incidence of EoE varied depending on the geographic location from 0.7 to $10 / 100,000$ per person-year and the prevalence ranged from 0.2 to $43 / 100,000$ children and increased over time. 
The pooled prevalence of EoE was 3.7\% in esophagogastroduodenoscopy performed for any indication, $24 \%$ in histologic esophageal disease, $2.3 \%$ in celiac disease and $2.6 \%$ in esophagogastroduodenoscopy performed for abdominal pain. The highest prevalence of EoE occurred in children with dysphagia and food impaction [16].

Similar findings have been reported from adult cohorts. A survey administered to members of the American College of Gastroenterology in 2008 (with a response rate of $17 \%$ ) revealed an estimated prevalence rate of $52 \mathrm{pa}-$ tients with EoE per 100,000 inhabitants [17]. In a national pathology database (Caris Diagnostics, Irving, Tex., USA), 363 cases of EoE from a cohort of upper endoscopies were identified in more than 74,000 upper endoscopies. A prevalence rate of approximately $0.5 \%$ per endoscopy was calculated. The prevalence of EoE increased significantly during the study period [18]. A review of esophageal biopsy specimens from 1992 to 2004 (pathology database at the University of Pennsylvania) showed a cumulative prevalence of $1.7 \%$ (10 cases per 584 reviewed esophageal biopsies), but 9 of 10 cases were identified in the years 2001-2004 [19], again indicating an increasing prevalence of EoE. An unexpectedly high prevalence rate of EoE of $6.5 \%$ was reported in a prospective study with 400 consecutively enrolled adult patients who underwent a routine upper endoscopy [20]. Interestingly, when patients are referred for an upper endoscopy due to dysphagia, a diagnosis of EoE can be established in $10-15 \%$ of the cases [21,22], with $11 \%$ due to food impactions [23]. Considerably higher rates are found when endoscopies were performed for the indication of bolus obstruction in children as an association with the diagnosis of EoE was found in up to $40 \%$ [24]. Patients older than 50 years with dysphagia are more likely to be diagnosed with $\mathrm{EoE}[21,22]$.

Based on these studies, we can conclude that the incidence and prevalence of pediatric and adult EoE has been increasing throughout the last years. However, it still needs to be determined whether this increase is based on an accumulation of EoE cases as the mortality from EoE is low, or whether it is based on an increasing incidence, as suggested by recent studies in geographically confined areas.

\section{Incidence and Prevalence of EoE in Geographically Confined Regions}

Several longitudinal studies have evaluated geographically confined regions and will be discussed here [2528]. In a retrospective and observational study in a geo- graphically isolated community of 198,000 inhabitants in Townsville (Qld., Australia), adult residents were diagnosed with EoE after review of physician, computerized endoscopic and hospital records [26]. Up to September 2002, a total of 31 patients had been diagnosed with EoE: no patients between 1981 and 1994, 12 patients between 1995 and 2000, and 19 patients between January 2001 and September 2002. This clearly indicates an increasing incidence of EoE in this area. At the end of 2002, the prevalence of EoE reached 15.6 patients per 100,000 inhabitants.

Castilla-La Mancha is a rural area located in the center of Spain with a population of approximately 102,000 inhabitants [25]. No relevant demographic changes were noted during the 2005-2011 study period in the region. Two gastroenterological departments served as referral centers for family physicians and emergency departments with a high awareness for EoE. The mean annual incidence rate of EoE during the study period was 6.37 per 100,000 inhabitants. The prevalence reached 44.6 cases per 100,000 inhabitants by the end of 2011. Interestingly, an unexpectedly high male-to-female ratio of 19:1 with an average age of 29.4 years was observed.

The Olten County area is situated in the northwestern part of Switzerland [27, 29]. The area, which has an urban/suburban character, had no relevant demographic changes and no structural changes to its medical system within the past decades. About 90,000 inhabitants live in this geographically circumscribed and socioeconomically stable region. Since 1989, EoE patients with PPI-refractory esophageal symptoms, EoE-consistent endoscopic abnormalities and a peak infiltration of the esophageal epithelium with $\geq 24$ eosinophils/HPF have been prospectively enrolled into a continuing community-based database. The diagnostic and enrolment procedures have remained almost unchanged over the past 20 years.

A recent analysis of this database showed that the incidence and prevalence of EoE has been substantially on the rise [27]. An annual incidence of 2.45 new EoE cases per 100,000 inhabitants per year was found with a pronounced increase in the last 6 years $(4.4-7.4 / 100,000)$. The prevalence increased to 43 patients per 100,000 inhabitants in 2009. This increase occurred in the face of a constant diagnostic delay (defined as the time interval from the onset of EoE-attributed symptoms to EoE diagnosis) assessed in two time intervals from 1989 to 1999 and from 2000 to 2009, with a median diagnostic delay of 3 years (interquartile range: $2-5$, range: $0-17 ; \mathrm{n}=10$ ) and of 2 years (interquartile range: $1-7$, range: $0-23 ; n=30$ ), as well as a lack of EoE awareness programs. 
Comparable results have been reported from Olmsted County, a geographically confined region in Minnesota (USA) with a population of 120,000 inhabitants [28] that sociodemographically mirrors the US white population. Residents of this county receive their medical care almost exclusively from two group practices. EoE patients were identified through the medical records storage system for this region (Rochester Epidemiology Project database) by an electronic search using the terms 'esophagitis' and 'food bolus impaction'. Patients having $\geq 15$ eosinophils/ HPF on endoscopy with esophageal biopsies were included in the analysis. The cumulative age- and gender-adjusted incidence rate between 1976 and 2005 was calculated to be $2.39(1.85-2.93)$ per 100,000 patient-years. The prevalence of EoE reached 55.0 per 100,000 inhabitants as of January 1, 2006. Analysis clearly indicated that the incidence of EoE increased over time, from 0.35 (1991$1995)$ to 9.45 per 100,000 person-years (2001-2005).

The results from these four studies indicate that the incidence and prevalence of EoE is increasing. The differences in the incidence and prevalence rates may be explained by the different threshold values for eosinophils per HPF used for the diagnosis of EoE, different geographical locations and different time frames when the studies were performed. Of note, by the end of 2002 the prevalence of EoE was approximately 16 patients per 100,000 inhabitants in Townsville County, 13 in Olten County, and 27 in Olmsted County. Considering the methodological differences between the three studies, it is roughly within the same range.

\section{Demographic Profile of EoE Patients}

\section{Age Distribution}

EoE can be found in all age groups, but most studies investigating adult EoE found the average age for subjects with EoE to be between 30 and 50 years, which suggests EoE is a disease of middle-aged adults $[18,20,21,26-28$, 30].

Several studies have reported a substantial time lag between the onset of symptoms and diagnosis (diagnostic delay), which in some cases can be attributed to unawareness of sentinel features at endoscopy and, as a result, the absence of histological evaluation [26]. A substantial proportion of the diagnostic delay must be attributed to the patients who learn to cope with their swallowing difficulties with evasive maneuvers, thereby postponing a medical consultation. Therefore, age at diagnosis does not at all correlate with the onset of EoE-attributed symptoms.
Croese et al. [26] described an average diagnostic delay of 54 months (range: $0-180$ ). The average duration between the onset of symptoms and diagnosis of EoE was reported to be 4.2 years (range: $0-44$ ) [31] in a German study and 4.8 years (range: $0-22$ ) in a study from Switzerland [29]. An updated analysis from the same Swiss database shows a median diagnostic delay of 3 years (1989-1999) and 2 years (2000-2009), which did not change significantly during the last two decades [27].

\section{Gender and Social Parameters}

EoE studies have concordantly demonstrated that males are significantly more affected with EoE than females, with $60-80 \%$ of all cases diagnosed being males. Analysis of studies with detailed demographic information of adult patients has shown that, on average, $76 \%$ of those affected were males, thereby suggesting a male-tofemale risk ratio of 3:1 [32].

Patients with EoE have been reported worldwide, but the vast majority of EoE cases and cohorts are reported from industrialized and westernized countries, such as the USA, Europe and Australia, whereas almost no reports come from tropical areas and/or developing countries [32]. EoE has been identified in a variety of ethnic backgrounds, including Caucasians, African Americans, Hispanics and Asians. So far, most studies have shown that Caucasians are the most frequently diagnosed group with EoE, but there is still insufficient epidemiological information about geographic variations of prevalence and it remains unclear whether clinical presentation of $\mathrm{EoE}$ is associated with any particular ethnic or racial background $[33,34]$. Interestingly, a prospective evaluation of routine endoscopy at a tertiary care military hospital in the USA revealed there was no significant difference between Caucasians (60\%) and African Americans (40\%), with no cases of EoE found among Hispanics or Asians [20]. However, because of this study's high overall EoE prevalence rate of $6.5 \%$ on routine upper endoscopy, these data should be interpreted with caution due to a possible selection bias, especially as other studies have not reported such high EoE prevalence rates on routine endoscopy.

EoE patients tend to live in affluent environments, are better educated and reside more often in urban/suburban areas when compared to the control groups; nevertheless, after adjustment for race and gender, these differences could no longer be confirmed [35]. These results notwithstanding, data from socioeconomic distribution are sparse and more systematic evaluations are needed to address the important questions of the contribution of environmental influences for the development of EoE. 


\section{Symptoms of Esophageal Dysfunction}

The most common presenting symptom of adult EoE is dysphagia for solids, sometimes leading to food impaction. Dysphagia is present in $70-100 \%$ of patients with EoE $[18,28,29,31]$. Children may present with a variety of symptoms. In addition to dysphagia and bolus obstruction, feeding disorder, failure to thrive, abdominal pain, heartburn and vomiting may occur $[10,13,36,37]$. Food impaction and/or the necessity for bolus removal ranges between 30 and $50 \%$ in most studies [20, 26, 28, $29,38]$. As a consequence of EoE's male predominance, it is not surprising that food impaction occurs more frequently in men $[38,39]$. Interestingly, patients evaluated for dysphagia or food impaction are reported to have EoE with a prevalence of $10-15 \%$, and are at a higher risk of being diagnosed with EoE if they are older than 50 years $[21,22]$. Patients presenting with dysphagia have been observed to have a significantly higher peak eosinophil count on biopsy specimens [18]. These prevalence rates may still underestimate the incidence of EoE as only $27 \%$ of patients with esophageal foreign body impaction had esophageal biopsies [40]. Symptoms resembling gastroesophageal reflux disease have been reported in different studies and range from 16 to $54 \%$ for EoE patients $[18,26,28,29,31]$. Symptoms of swallowing-associated chest pain and abdominal pain have also been reported in the literature. In summary, EoE is a leading cause of dysphagia and food impaction, especially in middle-aged men.

\section{Allergic Predisposition}

It has been proposed that in EoE eosinophils migrate to the esophagus in response to various ingested and/or inhaled allergens [41]. The specific patterns of cytokine expression resemble the findings of Th2-type inflammatory disorder also reported in other allergic diseases [42, 43]. Food allergens as well as aeroallergens have been implicated as contributing factors in inducing and maintaining the eosinophilic inflammation [32, 44, 45]. Indeed, patients with EoE show a history of seasonal allergies (40-50\%), asthma (30-40\%) and food allergies $(10-40 \%)[20,21,26,28,29]$. In a prospective evaluation, the prevalence of asthma was significantly higher in patients with EoE than in unaffected controls [20]. Similarly, though not significantly different, seasonal allergies and food allergies had a higher prevalence among the EoE-positive group. A case series of 23 adult EoE patients described a high degree of atopy with atopic diathesis in 18 of the 23 patients, with allergic rhinitis being the most common, and polysensitization to several environmental allergens in 17 of the 23 patients [46]. Multiple intervention studies in pediatric and adult EoE patients have identified food allergens as pathogenic factors of EoE. Specific skin-based elimination and six-food elimination diets have resulted in the resolution of symptoms and histological improvement in $>60 \%$ of affected pediatric and adult patients [47-55]. Amino acid-based elemental diets have been reported with even better success rates, but long-term adherence to these diets is difficult [5658]. Overall, food elimination diets show better success rates in children than in adults, and suggest that the pathophysiology of EoE in adults is more complex with frequent sensitization to aeroallergens [59]. This is consistent with the findings in a small case series of 6 adult EoE patients with known sensitization to wheat and rye where an elimination diet did not improve symptoms or endoscopic findings of EoE [60].

\section{EoE and Seasonal Distribution}

There is evidence that airborne antigens play a crucial role in the pathogenesis of EoE, and some reports have suggested a seasonal variation of EoE with EoE being more frequently diagnosed in the spring and summer seasons $[36,61,62]$. This is further supported by the observation that EoE varies by climate zones in the USA [63]. A confirmation of a seasonal dependency of EoE would be an indicator that external seasonal factors (especially pollen) could play a substantial role in the pathogenesis of this Th2-type inflammation. Indeed, one study has shown a significant correlation with the peak grass pollen count and diagnosis of EoE in the spring; however, only a coincidental association with the peak pollen counts of tree or weed was found [64]. It is important to consider that there is a substantial gap between the onset of symptoms (i.e. likely onset of disease) and endoscopic and histological diagnosis. Furthermore, the onset of disease often does not correlate with the date of diagnosis. Taken together, there is currently no solid proof that either the first onset of EoE or the course of its inflammation show a seasonal variation, or that pollen exposure could play a significant pathogenic role. One might speculate that patients with seasonal allergies would be more susceptible to aeroallergens and might therefore be more likely to develop symptoms of esophageal dysfunction. However, prospective studies are needed using either a systematic 
assessment of the symptom course or of EoE's inflammatory activity in correlation to the pollen exposure to answer this question.

\section{Summary}

Over the last decade there have been multiple indications of a true and constant increase in the prevalence of EoE worldwide. Whether this increased prevalence is due to a real increase in incidence, the result of increased awareness by health care providers or because of the nonfatal nature of EoE adding more and more cases to the patient pool is still a matter of controversy. The best evidence for a true escalation comes from recent data from Switzerland [27]. These data suggest that these changes in incidence and prevalence most likely reflect a true increase as it has occurred in the face of a constant diagnostic delay and in the absence of any EoE awareness programs. These findings are comparable with retrospective analyses from other geographically confined regions in the United States, Europe and Australia and therefore provide solid evidence for a significant increase in EoE incidence $[10,12,25,26,28]$. However, there are also reports in the literature that the rising incidence of EoE is associated with increasing biopsy rates and that the diagnosis of EoE is still being missed or misinterpreted [65]. It was shown that diagnostic failure is frequently due to a delayed request for endoscopy in patients with dysphagia, poor recognition of typical endoscopic appearances of EoE, and failed recognition or recording of maximal eosinophil concentrations within biopsies [66]. This indicates that in spite of established consensus recommendations for the diagnosis of EoE, health care professionals such as gastroenterologists, allergists, general practitioners and pathologists who encounter EoE need to increase the awareness to facilitate diagnosis of this still relatively new disease.

\section{Disclosure Statement}

The author has no conflicts to declare regarding this article.

\section{References}

1 Attwood SE, Smyrk TC, Demeester TR, Jones JB: Esophageal eosinophilia with dysphagia. A distinct clinicopathologic syndrome. Dig Dis Sci 1993;38:109-116.

-2 Straumann A, Spichtin HP, Bernoulli R, Loosli J, Vogtlin J: Idiopathic eosinophilic esophagitis: a frequently overlooked disease with typical clinical aspects and discrete endoscopic findings (in German). Schweiz Med Wochenschr 1994;124:1419-1429.

3 Liacouras CA, Furuta GT, Hirano I, Atkins D, Attwood SE, Bonis PA, Burks AW, Chehade M, Collins MH, Dellon ES, Dohil R, Falk GW, Gonsalves N, Gupta SK, Katzka DA, Lucendo AJ, Markowitz JE, Noel RJ, Odze RD, Putnam PE, Richter JE, Romero Y, Ruchelli E, Sampson HA, Schoepfer A, Shaheen NJ, Sicherer SH, Spechler S, Spergel JM, Straumann A, Wershil BK, Rothenberg ME, Aceves SS: Eosinophilic esophagitis: updated consensus recommendations for children and adults. J Allergy Clin Immunol 2011;128:3-20.e26, quiz 21-22.

4 Ahmad M, Soetikno RM, Ahmed A: The differential diagnosis of eosinophilic esophagitis. J Clin Gastroenterol 2000;30:242-244.

5 Ronkainen J, Talley NJ, Aro P, Storskrubb T, Johansson SE, Lind T, Bolling-Sternevald E, Vieth M, Stolte M, Walker MM, Agreus L: Prevalence of oesophageal eosinophils and eosinophilic oesophagitis in adults: the population-based Kalixanda study. Gut 2007;56: 615-620.
6 Foroutan M, Norouzi A, Molaei M, Mirbagheri SA, Irvani S, Sadeghi A, Derakhshan F, Tavassoli S, Besharat S, Zali M: Eosinophilic esophagitis in patients with refractory gastroesophageal reflux disease. Dig Dis Sci 2010;55: $28-31$.

7 DeBrosse CW, Collins MH, Buckmeier Butz BK, Allen CL, King EC, Assa'ad AH, Abonia JP, Putnam PE, Rothenberg ME, Franciosi JP: Identification, epidemiology, and chronicity of pediatric esophageal eosinophilia, 19821999. J Allergy Clin Immunol 2010;126:112119.

-8 Ravi K, Talley NJ, Smyrk TC, Katzka DA, Kryzer L, Romero Y, Arora AS, Alexander JA: Low grade esophageal eosinophilia in adults: an unrecognized part of the spectrum of eosinophilic esophagitis? Dig Dis Sci 2011;56: 1981-1986.

\$ van Rhijn BD, Verheij J, Smout AJ, Bredenoord AJ: Rapidly increasing incidence of eosinophilic esophagitis in a large cohort. Neurogastroenterol Motil 2013;25:47-52.

10 Noel RJ, Putnam PE, Rothenberg ME: Eosinophilic esophagitis. N Engl J Med 2004;351: 940-941.

11 Aceves SS, Newbury RO, Dohil R, Schwimmer J, Bastian JF: Distinguishing eosinophilic esophagitis in pediatric patients: clinical, endoscopic, and histologic features of an emerging disorder. J Clin Gastroenterol 2007;41: 252-256.
12 Cherian S, Smith NM, Forbes DA: Rapidly increasing prevalence of eosinophilic oesophagitis in Western Australia. Arch Dis Child 2006;91:1000-1004.

13 Gill R, Durst P, Rewalt M, Elitsur Y: Eosinophilic esophagitis disease in children from West Virginia: a review of the last decade (1995-2004). Am J Gastroenterol 2007;102: 2281-2285.

14 Lai AL, Girgis S, Liang Y, Carr S, Huynh HQ: Diagnostic criteria for eosinophilic esophagitis: a 5-year retrospective review in a pediatric population. J Pediatr Gastroenterol Nutr 2009;49:63-70

15 Dalby K, Nielsen RG, Kruse-Andersen S, Fenger C, Bindslev-Jensen C, Ljungberg S, Larsen K, Walsted AM, Husby S: Eosinophilic oesophagitis in infants and children in the region of southern Denmark: a prospective study of prevalence and clinical presentation. J Pediatr Gastroenterol Nutr 2010;51:280282.

-16 Soon IS, Butzner JD, Kaplan GG, deBruyn JC: Incidence and prevalence of eosinophilic esophagitis in children. J Pediatr Gastroenterol Nutr 2013;57:72-80.

17 Spergel JM, Book WM, Mays E, Song L, Shah SS, Talley NJ, Bonis PA: Variation in prevalence, diagnostic criteria, and initial management options for eosinophilic gastrointestinal diseases in the United States. J Pediatr Gastroenterol Nutr 2011;52:300-306. 
$\checkmark 18$ Kapel RC, Miller JK, Torres C, Aksoy S, Lash R, Katzka DA: Eosinophilic esophagitis: a prevalent disease in the United States that affects all age groups. Gastroenterology 2008; 134:1316-1321.

19 Whitney-Miller CL, Katzka D, Furth EE: Eosinophilic esophagitis: a retrospective review of esophageal biopsy specimens from 1992 to 2004 at an adult academic medical center. Am J Clin Pathol 2009;131:788-792.

-20 Veerappan GR, Perry JL, Duncan TJ, Baker TP, Maydonovitch C, Lake JM, Wong RK, Osgard EM: Prevalence of eosinophilic esophagitis in an adult population undergoing upper endoscopy: a prospective study. Clin Gastroenterol Hepatol 2009;7:420-426. e1-e2.

21 Mackenzie SH, Go M, Chadwick B, Thomas K, Fang J, Kuwada S, Lamphier S, Hilden K, Peterson K: Eosinophilic oesophagitis in patients presenting with dysphagia - a prospective analysis. Aliment Pharmacol Ther 2008; 28:1140-1146.

-22 Prasad GA, Talley NJ, Romero Y, Arora AS, Kryzer LA, Smyrk TC, Alexander JA: Prevalence and predictive factors of eosinophilic esophagitis in patients presenting with dysphagia: a prospective study. Am J Gastroenterol 2007;102:2627-2632.

23 Byrne KR, Panagiotakis PH, Hilden K, Thomas KL, Peterson KA, Fang JC: Retrospective analysis of esophageal food impaction: differences in etiology by age and gender. Dig Dis Sci 2007;52:717-721.

24 El-Matary W, El-Hakim H, Popel J: Eosinophilic esophagitis in children needing emergency endoscopy for foreign body and food bolus impaction. Pediatr Emerg Care 2012; 28:611-613.

25 Arias A, Lucendo AJ: Prevalence of eosinophilic oesophagitis in adult patients in a central region of Spain. Eur J Gastroenterol Hepatol 2013;25:208-212.

26 Croese J, Fairley SK, Masson JW, Chong AK, Whitaker DA, Kanowski PA, Walker NI: Clinical and endoscopic features of eosinophilic esophagitis in adults. Gastrointest Endosc 2003;58:516-522.

-27 Hruz P, Straumann A, Bussmann C, Heer P, Simon HU, Zwahlen M, Beglinger C, Schoepfer AM: Escalating incidence of eosinophilic esophagitis: a 20 -year prospective, population-based study in Olten County, Switzerland. J Allergy Clin Immunol 2011;128:13491350.

28 Prasad GA, Alexander JA, Schleck CD, Zinsmeister AR, Smyrk TC, Elias RM, Locke GR 3rd, Talley NJ: Epidemiology of eosinophilic esophagitis over three decades in Olmsted County, Minnesota. Clin Gastroenterol Hepatol 2009;7:1055-1061.

-29 Straumann A, Simon HU: Eosinophilic esophagitis: escalating epidemiology? J Allergy Clin Immunol 2005;115:418-419.
30 Altun R, Akbas E, Yildirim AE, Ocal S, Korkmaz M, Selcuk H: Frequency of eosinophilic esophagitis in patients with esophageal symptoms: a single-center Turkish experience. Dis Esophagus 2012;26:776-781.

31 Müller S, Pühl S, Vieth M, Stolte M: Analysis of symptoms and endoscopic findings in 117 patients with histological diagnoses of eosinophilic esophagitis. Endoscopy 2007;39:339344.

32 Furuta GT, Liacouras CA, Collins MH, Gupta SK, Justinich C, Putnam PE, Bonis P, Hassall E, Straumann A, Rothenberg ME: Eosinophilic esophagitis in children and adults: a systematic review and consensus recommendations for diagnosis and treatment. Gastroen terology 2007; 133:1342-1363.

33 Moawad FJ, Veerappan GR, Dias JA, Maydonovitch CL, Wong RK: Race may play a role in the clinical presentation of eosinophilic esophagitis. Am J Gastroenterol 2012;107: 1263.

- 34 Sperry SL, Woosley JT, Shaheen NJ, Dellon ES: Influence of race and gender on the presentation of eosinophilic esophagitis. Am J Gastroenterol 2012;107:215-221.

35 Franciosi JP, Tam V, Liacouras CA, Spergel JM: A case-control study of sociodemographic and geographic characteristics of 335 children with eosinophilic esophagitis. Clin Gastroenterol Hepatol 2009;7:415-419.

36 Iwanczak B, Janczyk W, Ryzko J, Banaszkiewicz A, Radzikowski A, Jarocka-Cyrta E, Kaczmarski M, Czkwianianc E, Korczowski B, Czaja-Bulsa G, Zielinska I, CzerwionkaSzaflarska M, Kwiecien J, Ogrodowska M, Daukszewicz A, Pytrus T, Iwanczak F: Eosinophilic esophagitis in children: frequency, clinical manifestations, endoscopic findings, and seasonal distribution. Adv Med Sci 2011; 56:151-157.

- 37 Thakkar K, Chen L, Tatevian N, Shulman RJ, McDuffie A, Tsou M, Gilger MA, El-Serag HB: Diagnostic yield of oesophagogastroduodenoscopy in children with abdominal pain. Aliment Pharmacol Ther 2009;30:662-669.

- 38 Kerlin P, Jones D, Remedios M, Campbell C: Prevalence of eosinophilic esophagitis in adults with food bolus obstruction of the esophagus. J Clin Gastroenterol 2007;41:356361.

- 39 Desai TK, Stecevic V, Chang CH, Goldstein NS, Badizadegan K, Furuta GT: Association of eosinophilic inflammation with esophageal food impaction in adults. Gastrointest Endosc 2005;61:795-801.

40 Sperry SL, Crockett SD, Miller CB, Shaheen NJ, Dellon ES: Esophageal foreign-body impactions: epidemiology, time trends, and the impact of the increasing prevalence of eosinophilic esophagitis. Gastrointest Endosc 2011; 74:985-991.

41 Straumann A, Bauer M, Fischer B, Blaser K, Simon HU: Idiopathic eosinophilic esophagitis is associated with a $\mathrm{T}(\mathrm{H}) 2$-type allergic inflammatory response. J Allergy Clin Immunol 2001;108:954-961.
42 Akdis CA, Akdis M, Simon D, Dibbert B, Weber M, Gratzl S, Kreyden O, Disch R, Wuthrich B, Blaser K, Simon HU: T cells and T cellderived cytokines as pathogenic factors in the nonallergic form of atopic dermatitis. J Invest Dermatol 1999;113:628-634.

43 Bousquet J, Vignola AM, Demoly P: Links between rhinitis and asthma. Allergy 2003;58: 691-706.

44 Arora AS, Yamazaki K: Eosinophilic esophagitis: asthma of the esophagus? Clin Gastroenterol Hepatol 2004;2:523-530.

45 Rothenberg ME, Mishra A, Collins MH, Putnam PE: Pathogenesis and clinical features of eosinophilic esophagitis. J Allergy Clin Immunol 2001;108:891-894.

46 Roy-Ghanta S, Larosa DF, Katzka DA: Atopic characteristics of adult patients with eosinophilic esophagitis. Clin Gastroenterol Hepatol 2008;6:531-535.

47 Gonsalves N, Yang GY, Doerfler B, Ritz S, Ditto AM, Hirano I: Elimination diet effectively treats eosinophilic esophagitis in adults; food reintroduction identifies causative factors. Gastroenterology 2012;142:1451-1459.

48 Henderson CJ, Abonia JP, King EC, Putnam PE, Collins MH, Franciosi JP, Rothenberg ME: Comparative dietary therapy effectiveness in remission of pediatric eosinophilic esophagitis. J Allergy Clin Immunol 2012; 129:1570-1578.

49 Kagalwalla AF, Amsden K, Shah A, Ritz S, Manuel-Rubio M, Dunne K, Nelson SP, Wershil BK, Melin-Aldana H: Cow's milk elimination: a novel dietary approach to treat eosinophilic esophagitis. J Pediatr Gastroenterol Nutr 2012;55:711-716.

50 Kagalwalla AF, Sentongo TA, Ritz S, Hess T, Nelson SP, Emerick KM, Melin-Aldana H, Li BU: Effect of six-food elimination diet on clinical and histologic outcomes in eosinophilic esophagitis. Clin Gastroenterol Hepatol 2006;4:1097-1102.

51 Kagalwalla AF, Shah A, Li BU, Sentongo TA, Ritz S, Manuel-Rubio M, Jacques K, Wang D, Melin-Aldana H, Nelson SP: Identification of specific foods responsible for inflammation in children with eosinophilic esophagitis successfully treated with empiric elimination diet. J Pediatr Gastroenterol Nutr 2011;53: 145-149.

52 Lucendo AJ, Arias A, Gonzalez-Cervera J, Yague-Compadre JL, Guagnozzi D, Angueira $\mathrm{T}$, Jimenez-Contreras S, Gonzalez-Castillo S, Rodriguez-Domingez B, De Rezende LC, Tenias JM: Empiric 6-food elimination diet induced and maintained prolonged remission in patients with adult eosinophilic esophagitis: a prospective study on the food cause of the disease. J Allergy Clin Immunol 2013;131: 797-804.

53 Spergel JM, Andrews T, Brown-Whitehorn TF, Beausoleil JL, Liacouras CA: Treatment of eosinophilic esophagitis with specific food elimination diet directed by a combination of skin prick and patch tests. Ann Allergy Asthma Immunol 2005;95:336-343. 
54 Spergel JM, Beausoleil JL, Mascarenhas M, Liacouras CA: The use of skin prick tests and patch tests to identify causative foods in eosinophilic esophagitis. J Allergy Clin Immunol 2002;109:363-368.

55 Spergel JM, Brown-Whitehorn TF, Cianferoni A, Shuker M, Wang ML, Verma R, Liacouras CA: Identification of causative foods in children with eosinophilic esophagitis treated with an elimination diet. J Allergy Clin Immunol 2012;130:461-467.

56 Kelly KJ, Lazenby AJ, Rowe PC, Yardley JH, Perman JA, Sampson HA: Eosinophilic esophagitis attributed to gastroesophageal reflux: improvement with an amino acid-based formula. Gastroenterology 1995;109:15031512.

57 Markowitz JE, Spergel JM, Ruchelli E, Liacouras CA: Elemental diet is an effective treatment for eosinophilic esophagitis in children and adolescents. Am J Gastroenterol 2003;98: 777-782.
Peterson KA, Byrne KR, Vinson LA, Ying J, Boynton KK, Fang JC, Gleich GJ, Adler DG, Clayton F: Elemental diet induces histologic response in adult eosinophilic esophagitis. Am J Gastroenterol 2013;108:759-766.

59 Simon D, Marti H, Heer P, Simon HU, Braathen LR, Straumann A: Eosinophilic esophagitis is frequently associated with IgE-mediated allergic airway diseases. J Allergy Clin Immunol 2005;115:1090-1092.

-60 Simon D, Straumann A, Wenk A, Spichtin H, Simon HU, Braathen LR: Eosinophilic esophagitis in adults - no clinical relevance of wheat and rye sensitizations. Allergy 2006;61:14801483 .

61 Almansa C, Krishna M, Buchner AM, Ghabril MS, Talley N, DeVault KR, Wolfsen H, Raimondo M, Guarderas JC, Achem SR: Seasonal distribution in newly diagnosed cases of eosinophilic esophagitis in adults. Am J Gastroenterol 2009;104:828-833.

62 Wang FY, Gupta SK, Fitzgerald JF: Is there a seasonal variation in the incidence or intensity of allergic eosinophilic esophagitis in newly diagnosed children? J Clin Gastroenterol 2007;41:451-453.
63 Hurrell JM, Genta RM, Dellon ES: Prevalence of esophageal eosinophilia varies by climate zone in the United States. Am J Gastroenterol 2012;107:698-706.

-64 Moawad FJ, Veerappan GR, Lake JM, Maydonovitch CL, Haymore BR, Kosisky SE, Wong RK: Correlation between eosinophilic oesophagitis and aeroallergens. Aliment Pharmacol Ther 2010;31:509-515.

65 Syed AA, Andrews CN, Shaffer E, Urbanski SJ, Beck P, Storr M: The rising incidence of eosinophilic oesophagitis is associated with increasing biopsy rates: a population-based study. Aliment Pharmacol Ther 2012;36:950958.

66 Kanakala V, Lamb CA, Haigh C, Stirling RW, Attwood SE: The diagnosis of primary eosinophilic oesophagitis in adults: missed or misinterpreted? Eur J Gastroenterol Hepatol 2010;22:848-855. 